\title{
TIVA for ECMO and VAD
}

\author{
Poonam Malhotra Kapoor ${ }^{1}$ Sandeep Sharan ${ }^{1}$ Minati Choudhury ${ }^{1}$
}

${ }^{1}$ Department of Cardiac Anaesthesia, CTC, AlIMS, New Delhi, India

Address for correspondence Poonam Malhotra Kapoor, MD, DNB, MNAMS, FIACTA, FTEE, FISCU, Department of Cardiac Anaesthesia, CTC, AIIMS, New Delhi, India (e-mail: drpoonamaiims@gmail.com).
Abstract
Keywords
- ECMO
- TIVA
$-V A D$

In recent decades, the use of temporary and permanent use of mechanical assist devices is on the rise for patients with end-stage cardiac failure. These support strategies hold inherently different risks in the face of noncardiac critical illness and require multidisciplinary treatment strategies. The main issues with all mechanical devices whether extracorporeal membrane oxygenation (ECMO) or ventricular assist device (VAD), are related to thrombosis, anticoagulation, infection, avoiding hypertension and thus use of intravenous drugs, which requires intense monitoring, to circumvent further renal, ischemic or neurological injury and prevent complication.
"It is not the strongest or the most intelligent who will survive but those who can best manage change."Leon c. Megginson

In recent decades, the use of temporary and permanent mechanical assist devices are on the rise for patients with endstage cardiac failure. These support strategies hold inherently different risks in the face of noncardiac critical illness and require multidisciplinary treatment strategies. The main issues with all mechanical devices, whether extracorporeal membrane oxygenation (ECMO) or ventricular assist device (VAD), are related to thrombosis, anticoagulation, infection, and avoiding hypertension. Thus, use of intravenous drugs requires intense monitoring to circumvent further renal, ischemic or neurological injury, and prevent complications (-Fig. 1).

The goal of drug therapy is to maximize efficacy and minimize toxicity. Critical illness and ECMO alter the pharmacokinetics (PK) and pharmacodynamics (PD) of medications significantly; therefore, the risk of therapeutic failure or toxicity is heightened in this patient population. ${ }^{1,2}$ Clearance of medications in critically ill patients is typically dependent upon renal or hepatic function, and it can increase or decrease, depending upon the underlying disease process. $^{3}$ Complex changes in PK parameters occur with ECMO initiation and maintenance, with an increased volume of distribution, altered clearance, and sequestration of drugs in the ECMO circuitry. ${ }^{4}$ Failure to account for these alterations in PK can lead to therapeutic failure, and drug monitoring is critical for appropriate treatment outcomes when feasible. ECMO alters the PK of sedative, analgesic, and antibiotic drugs, and their metabolites, independent of other associated patient and pathological factors. Drug molecular size, degree of ionization, lipophilicity, and plasma protein binding (PPB), all contribute significantly to adult, pediatric, and neonatal ECMO PK studies. Drugs with a high lipophilicity or protein binding $(\mathrm{PB})$ have greater degradation or loss in the ECMO circuitry. ${ }^{5-10}$ Significant sequestration occurs primarily in the oxygenator due to its large surface area. The type and age of the components (oxygenator, pump, and tubing) also contribute to the degree of sequestration. ${ }^{11-14}$

\section{Day 3 Postpartum Case of Cardiomyopathy}

Let us take a clinical case scenario case of a $62 \mathrm{~kg}, 170 \mathrm{~cm}$ female with a respiration rate (RR) of 18 and Rt right arm, BP supine: 92/66 mm Hg with a heart rate (HR) of 118/min/ SR; on auscultation, she had a gallop rhythm and 3/6 murmur in the apex (mitral regurgitation [MR]). Pulmonary RR was $18 / \mathrm{min}$ with right pleural effusion, liver $10 \mathrm{~cm}$ in midclavicular line (MCL) and peripheral edema ( - Fig. 2, Fig. 3). published online March 27, 2021
DOI https://doi.org/

$10.1055 / \mathrm{s}-0041-1728228$ ISSN 2457-0206
(O)2021. Official Publication of The Simulation Society (TSS), accredited by International Society of Cardiovascular Ultrasound (ISCU).

This is an open access article published by Thieme under the terms of the Creative Commons Attribution-NonDerivative-NonCommercial-License, permitting copying and reproduction so long as the original work is given appropriate credit. Contents may not be used for commercial purposes, or adapted, remixed, transformed or built upon. (https://creativecommons.org/licenses/by-nc-nd/4.0/).

Thieme Medical and Scientific Publishers Pvt. Ltd. A-12, 2nd Floor, Sector 2, Noida-201301 UP, India 

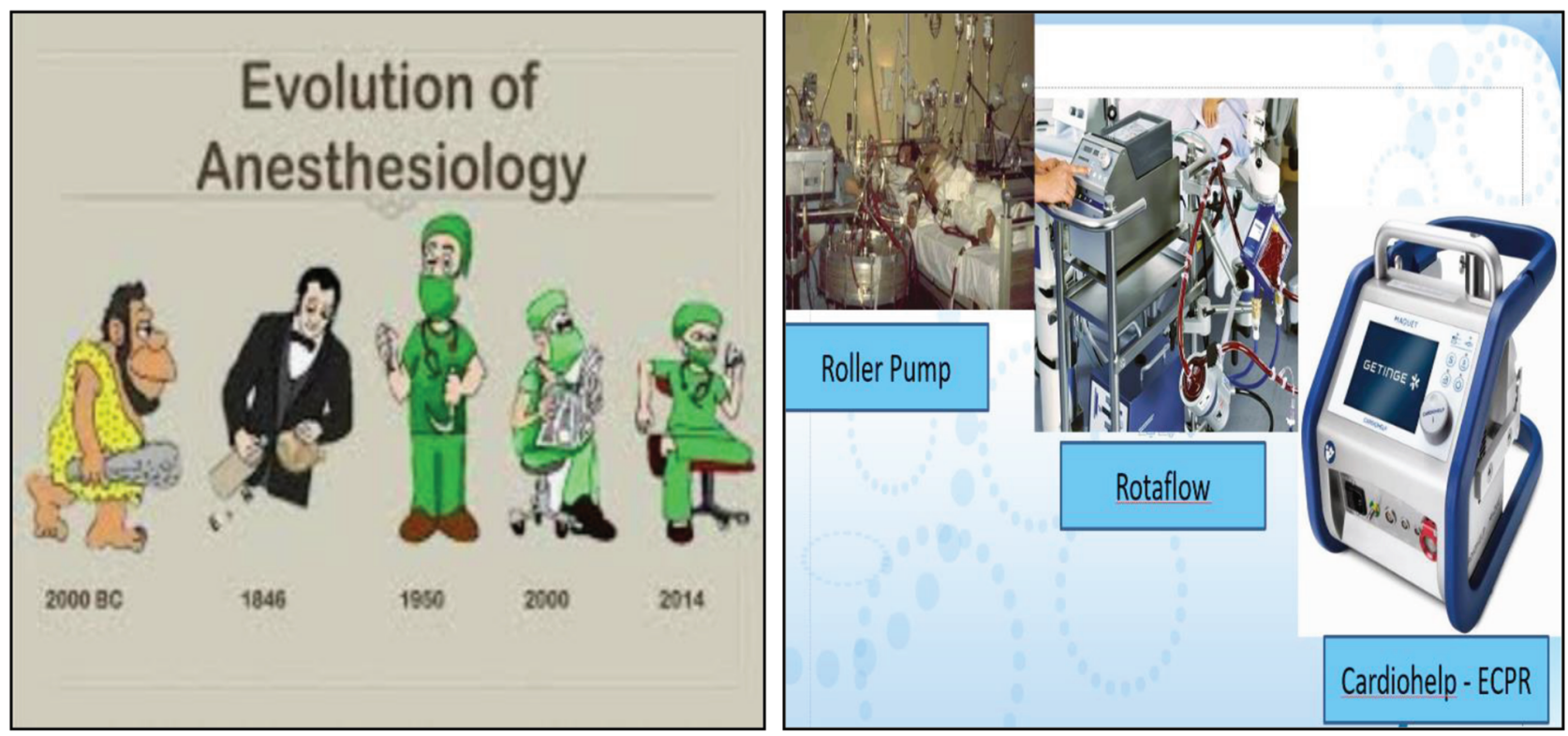

Fig. 1 Evolution is the only change that is needed for an anesthesiologist. The extracorporeal membrane oxygenation (ECMO) machine has evolved technically and scientifically like the anesthesiologist.
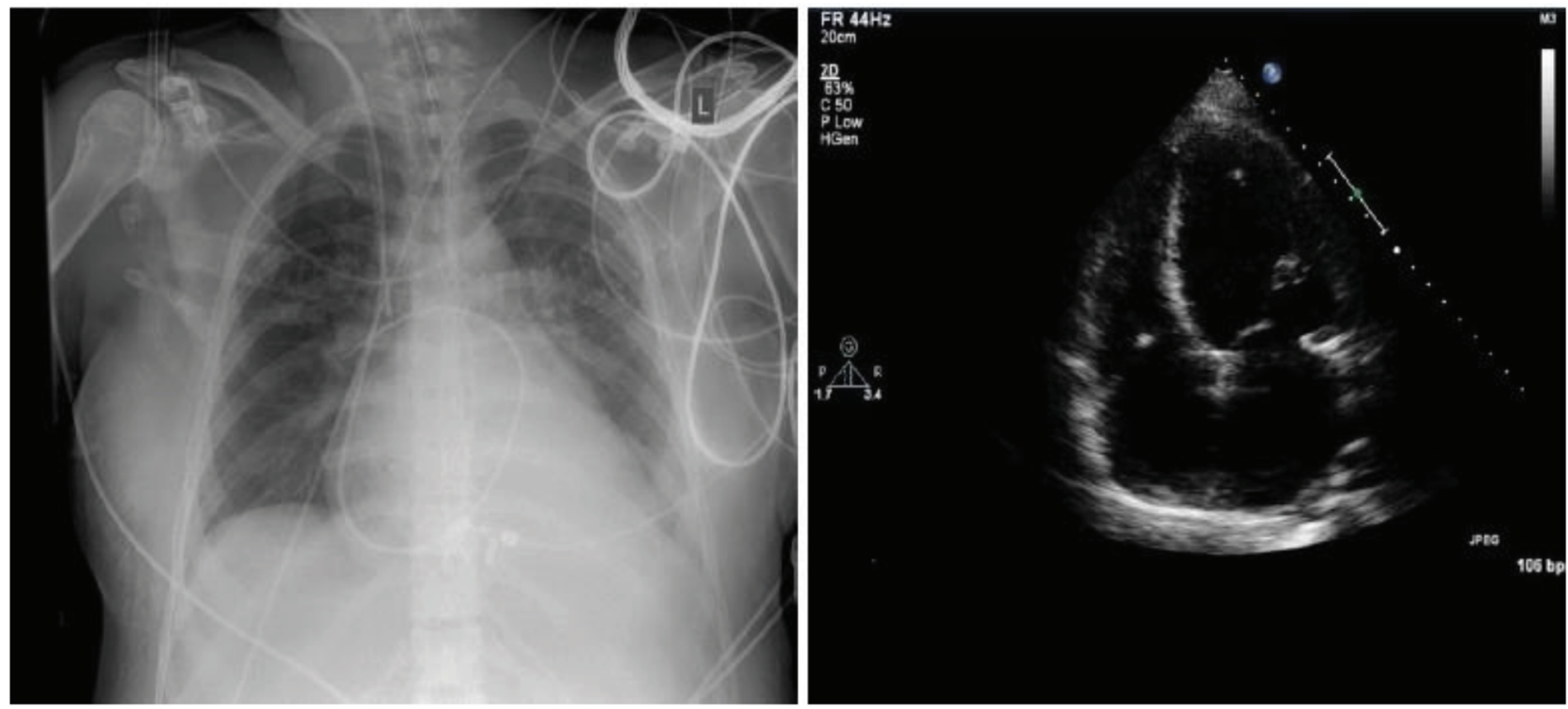

Fig. 2 Postpartum cardiomyopathy X-ray chest and echocardiography showing pulmonary edema and right ventricular (RV) strain.

The New Acute Heart Failure Guidelines Suggest a Temporary support: ECMO or VAD?

\section{Cardiogenic Shock}

Compromise of cardiac output leads to end-organ hypoperfusion. Complex cascade of end-organ dysfunction combined with activation of inflammatory pathways complicate approximately $7 \%$ of ST-segment elevation myocardial infarction (STEMI) and approximately $2.5 \%$ of non-ST-segment elevation MI (NSTEMI) in a case of cardiogenic shock on ECMO (-Fig. 3).

ECMO is a rescue therapy used to provide cardiac and/or respiratory support for critically ill patients in whom maximal conventional medical management has failed.
Venovenous (VV) ECMO: provides adequate oxygenation and carbon dioxide removal in isolated refractory respiratory failure. Venoarterial (VA) ECMO: when support is required for cardiac and/or respiratory failure. During ECMO support, coagulation and anticoagulation processes are activated, and a state of equilibrium is a challenge to all. Appropriate anticoagulation management is essential in these patients or else clots can be seen on the oxygenator $(- \text { Fig. } 3)^{15}$

\section{Extending Horizons of ECMO}

Can the Tight Rope of Anticoagulation Help Further?

We believe that patients with acute heart failure (AHF) can be supported on ECMO, but extreme precaution must be taken 


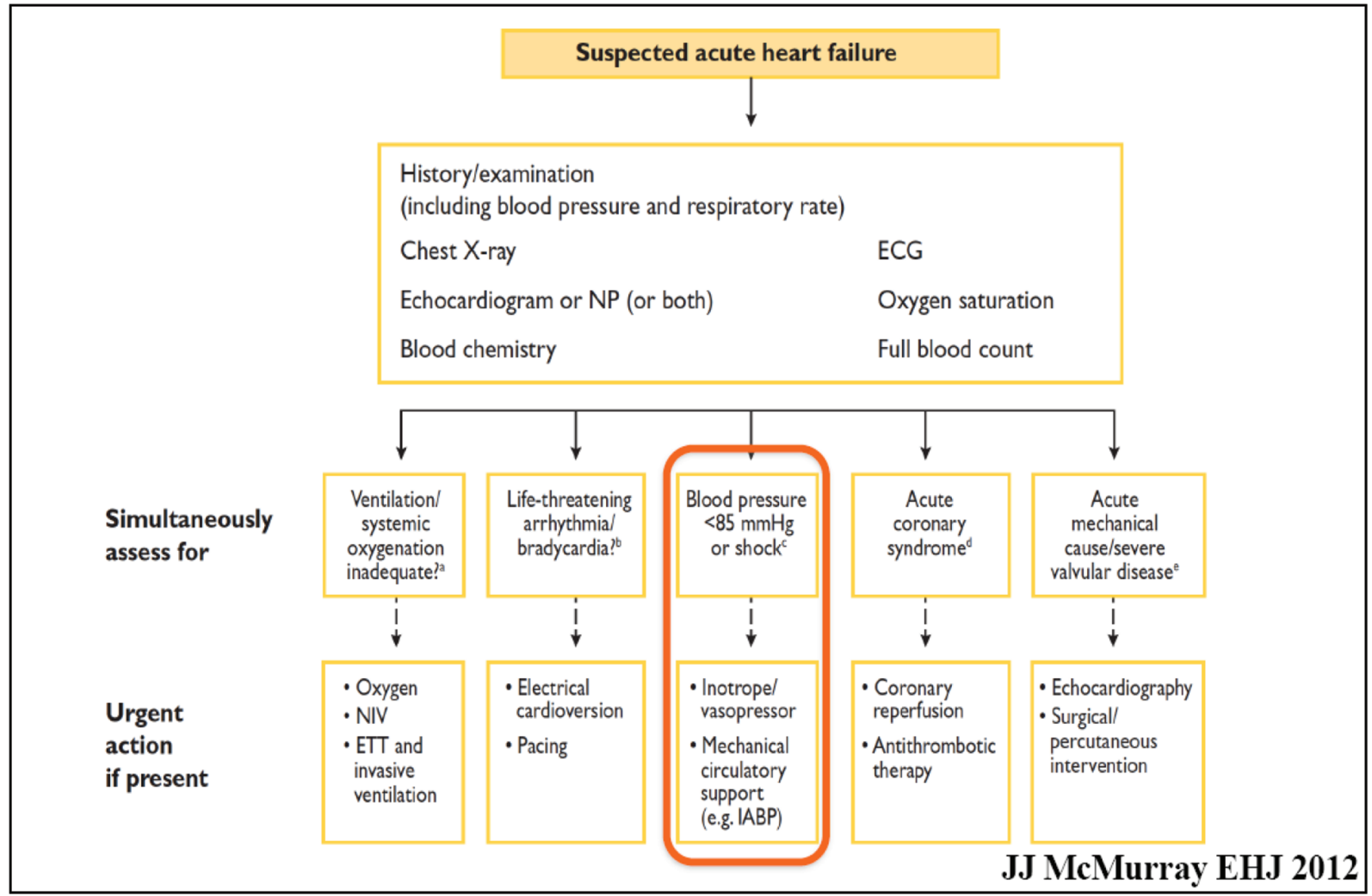

Fig. 3 Acute heart failure (AHF)-What do the new guidelines say? The guidelines in 2012 itself suggested use of mechanical support below $85 \mathrm{~mm} \mathrm{Hg}$, when the mean arterial pressure (MAP) fell in a patient with AHF.
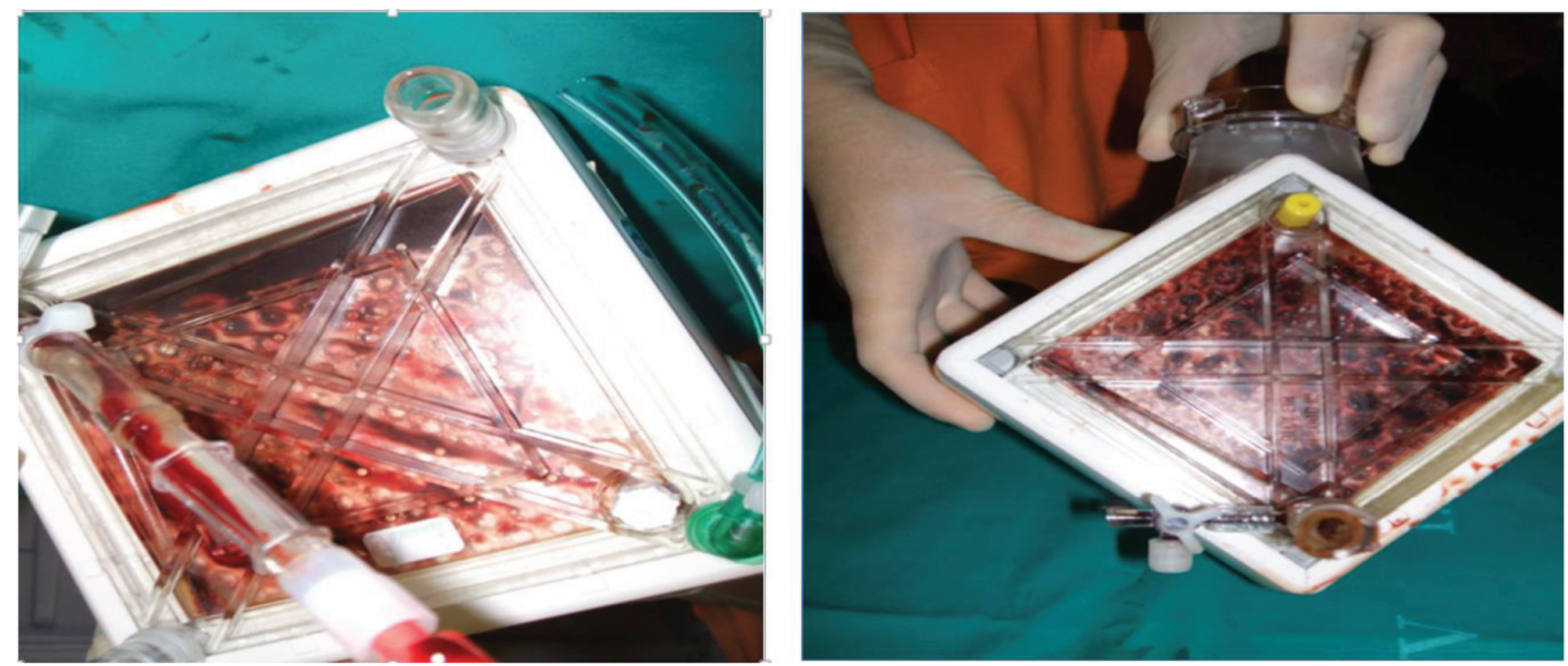

Fig. 4 Clotting of oxygenator as seen enface with a torch on the maquet quadrox oxygenator of the extracorporeal membrane oxygenation (ECMO) circuit.

regarding anticoagulation. The newer strategies of anticoagulation and the advances in coagulation monitoring can help in such lifesaving neurosurgical intervention during ECMO support, which would extend the horizons of ECMO. ${ }^{15}$

\section{Do We Need ECMO for Our COVID Patient in 2021?}

Intraventricular thrombosis is a well-known complication of MI. ECMO and left ventricular (LV) akinesis can increase this risk, and this, while on ECMO, should be observed with echocardiography and rectified (-Figs. 4, 5).

\section{COVID-19 ECMO Myths Busted in 2021}

Great dilemmas exist in the use of ECMO perplexities, such as do we treat the COVID-19 patients on ECMO, as a pulmonary ARDS pneumonia, and/or do we need high positive end-expiratory pressure (PEEP) or moderate PEEP? Do we manage patients with a wet or dry circuit for mucus plugging 


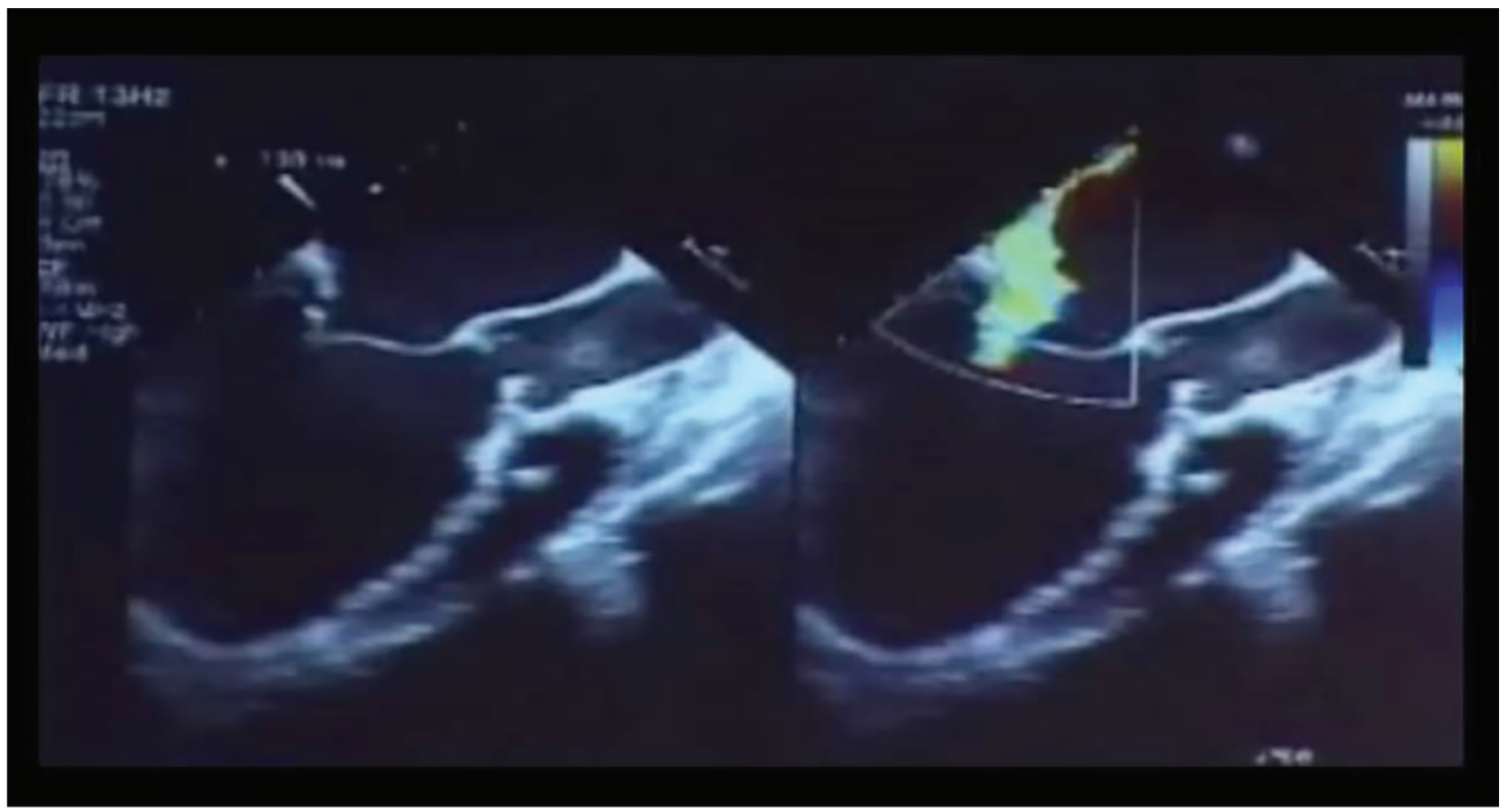

Fig. 5 Patient on venoarterial (VA) extracorporeal membrane oxygenation (ECMO) for severe systolic and diastolic mitral regurgitation (MR).
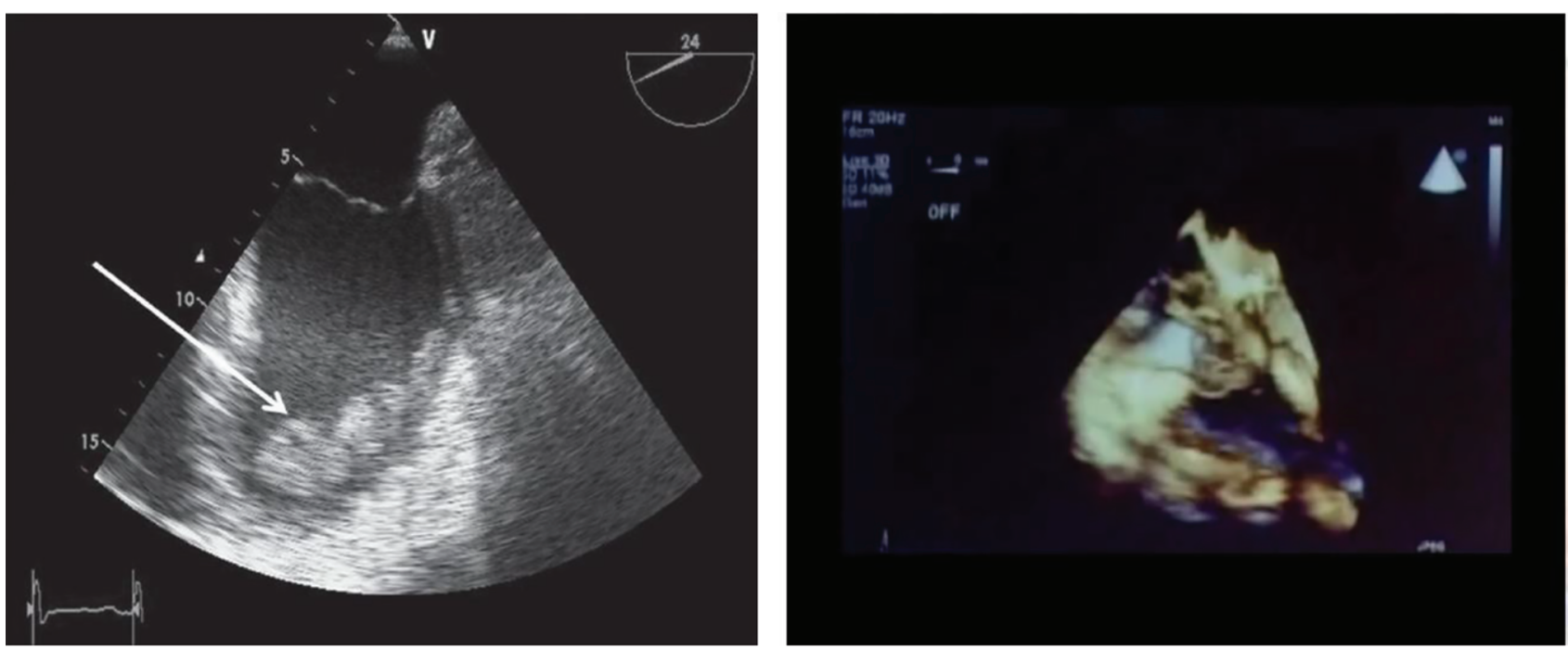

Fig. 6 Extracorporeal membrane oxygenation (ECMO) complications-thrombosis on 3D echocardiography. are well visualised.

and whether secretion management time and experience will be narrative? ${ }^{16}$

\section{Ventricular Assist Device (VAD)}

A mechanical pump that is surgically attached to one of the heart's ventricles to augment or replace native ventricular function can be used for the left (L VAD), right (R VAD), or both ventricles (Bi VAD). They are powered by external power sources that connect to the implanted pump via a percutaneous lead (driveline), which exits the body on the right abdomen. Pump output flow can be pulsatile or nonpulsatile (-Table 1).

\section{Principles of TIVA on ECMO and VAD}

The drugs on ECMO or VAD are administered using plasmatargeted models. The planned decrease in opioid concentration would increase the likelihood of response to a noxious stimulus and could increase the chance of awareness on total intravenous anesthesia (TIVA) use. An increase in propofol target from 2 to 3 ug mL- 1 to 5 to $6 \mu \mathrm{g} \mathrm{mL-1}$ would be needed to minimize such risk of awareness when the opioid that we are using (e.g., remifentanil) is in lower doses.

While using ECMO or VAD, on a patient, the drugs used to maintain sedation and analgesia are a cause for concern too. Instead of inhalational agents and intravenous drugs are preferred for these two modalities (-Table 2 ). 
Table 1 Indications for VAD

\begin{tabular}{|l|}
\hline$>$ BTT \\
- Most common \\
- Allow rehab from severe CHF while awaiting donor \\
\hline$>$ DT \\
- Permanent device, instead of transplant \\
- Currently only in transplant-ineligible patients \\
\hline$>$ BTR \\
- Unload heart, allow "reverse remodeling" \\
- Can be short- or long-term \\
\hline BTC/BTD \\
- When eligibility unclear at implant \\
- Not true "indication" but true for many patients
\end{tabular}

Abbreviations: BTC, bridge to candidacy; BTD, bridge to decision; BTR, bridge to recovery; $\mathrm{BTT}$, bridge to transplant; $\mathrm{CHF}$, congestive heart failure; DT, destination therapy.

Table 2 Recommendations for preventing technical problems with TIVA

\begin{tabular}{|l|}
\hline Recommendations \\
\hline Complete the TCI system checklist \\
\hline Affix the IV cannula firmly to the patient's skin \\
\hline Keep the site of TIVA infusion visible so that disconnection, \\
leakage, or a "tissued" cannula are readily detected \\
\hline Use only a dedicated two- or three-way TIVA set which \\
incorporates \\
- anti-siphon valves on the drug administration lines \\
- non-return valve on any IV fluid line \\
mixing \\
\hline$>$ Use only Luer lock syringes for administering drugs \\
\hline $\begin{array}{l}\text { Do not label the remifentanil syringe until the drug has been } \\
\text { added to the diluent }\end{array}$ \\
\hline $\begin{array}{l}\text { Always check the infusion site if a pump alarms (except } \\
\text { "syringe empty," "infusion paused," or "mains failure") }\end{array}$ \\
\hline $\begin{array}{l}\text { istration set before connection to the patient cannula, and out } \\
\text { of the cannula at the end of the case }\end{array}$ \\
Abbreviations: IV, intravenous; TCI, target-controlled infusion; TIVA, \\
total intravenous anesthesia.
\end{tabular}

\section{ECMO Alters the Pharmacokinetics (PK) of Most Drugs}

ECMO alters the PK of sedatives, analgesics, antibiotic drugs and their metabolites-drug molecular size, degree of ionization, lipophilicity, and PPB. High lipophilicity and PB drugs have greater loss and degradation in the ECMO circuitry. Degree of sequestration, type of oxygenator, circuit tubing, and type of pump. It is also a well-known fact that while on ECMO or VAD, the PK of most drugs is complicated due to sequestration and inactivation of most drugs (Fig. 7). A knowledge-driven improvement strategy necessitates sufficient understanding of human developmental biology to subsequently translate such knowledge into prediction differences in Drug absorption, Distribution, Metabolism, Excretion. • Only once this PK is sufficiently well-covered, an appreciation of the developmental aspects of drug-receptor or target interactions (PD) can be considered

\section{Pharmacokinetics of Drugs During ECMO}

The PK of drugs on ECMO is complicated by the volume of distribution, which is larger due to the ECMO circuit. Drug combination gets modified and circuit components may alter the PK due to drug absorption: Sequestration and inactivation of drugs is determined by drug and circuit interaction (Fig. 8, - Table 3).

\section{Drugs with a Higher Log Bond to the Silicon Oxygenator}

The dosages of drugs such as propofol, midazolam and variconazole must be increased for desired effects. An ex vivo study of fentanyl $(\log \mathrm{P} 4, \mathrm{~PB} 80 \%)$ in an ECMO circuit using a silicone membrane oxygenator showed $>99 \%$ fentanyl loss in 180 minutes (Fig. 10) ${ }^{17,18}$

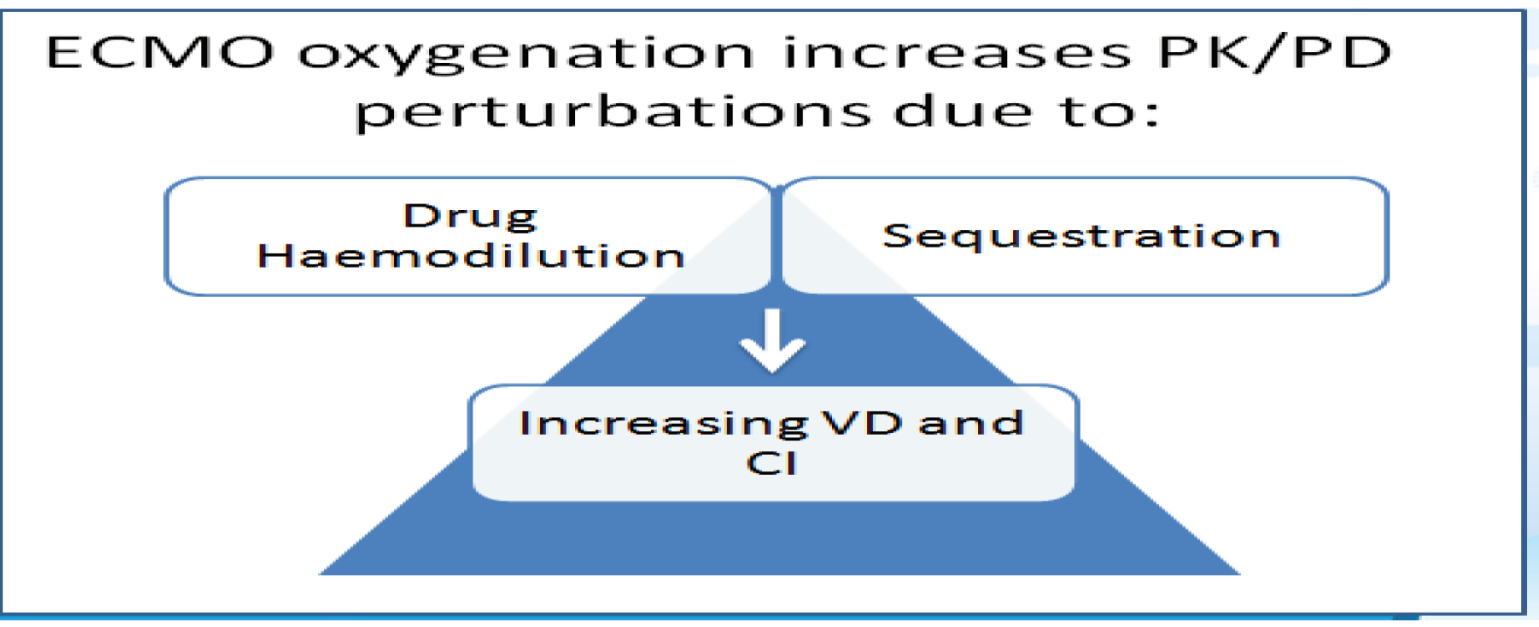

Fig. 7 Extracorporeal membrane oxygenation (ECMO) changes the pharmacokinetics (PK) and pharmacodynamics (PD) of most total intravenous anesthesia (TIVA) drugs. 


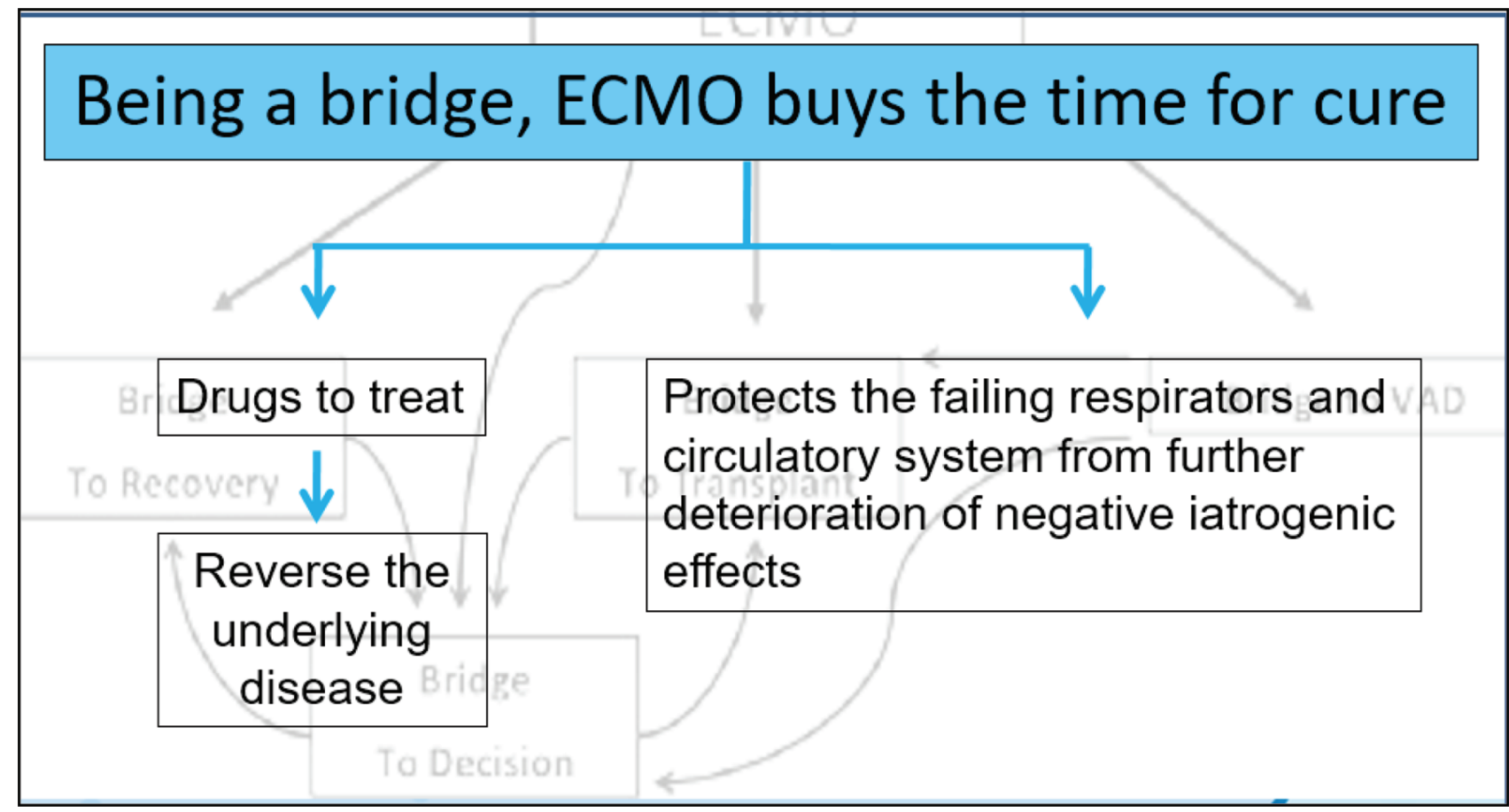

Fig. 8 Being a bridge, extracorporeal membrane oxygenation (ECMO) buys the time for cure.

Table 3 Determinants of drug disposition during ECMO

- Patient-related determined: development pharmacology, critical illness, volume status, comedications

- Drug-related determinants: lipophilicity, molecular size, protein binding, ionization degree

- Circuit-related determinants: components, materials, size, priming, flow setting

- Drug-patients interaction: impaired clearance, altered volume of distribution

- Drug-circuit interaction: multiple drug exposure, binding saturation, drug sequestration

Abbreviation: ECMO, extracorporeal membrane oxygenation.

\section{Disposition of Analog-Sedatives on Neonatal ECMO}

During ECMO, neonates are exposed to multiple sedatives and analgesics, mostly for prolonged periods, to provide comfort, pain relief, and safety. The extracorporeal circuit has a large impact on sedatives and analgesics disposition, leading to high-sedative needs. Drug physicochemical properties may assist in the dose prediction, which is titrated to clinical effect. Indeed, lipophilic agents, like fentanyl, propofol, and midazolam, are highly sequestered into the circuit, especially in the first hours of bypass. ${ }^{18}$

\section{Benzodiazepines}

Moderate sequestration into the circuit has been observed through in vitro experiments, based on both old and contemporary circuits. Two PK studies are available in the neonatal ECMO population, with contrasting results. Both described the increase of volume of distribution (Vd), since the start of ECMO. Mulla et al found a constant confidence interval (CI) of midazolam in neonates on VV ECMO, with a prolonged elimination half-life, leading to drug accumulation after 48 hours. ${ }^{19}$

\section{Opioids}

Fentanyl is highly sequestered into the circuit, and fentanyl dose escalation is required in patients exposed to extracorporeal circuits. Despite the technological improvements, the impact of contemporary hollow fiber-based oxygenators remains high for lipophilic drugs such as fentanyl and sufentanil. When compared with fentanyl, morphine continuous infusions were associated with improved analgesia and reduced drug withdrawal and length of stay. Morphine remains the opioid of choice for neonatal ECMO. Dose adjustments need to be titrated to clinical sedo-analgesic targets, pending evidence on contemporary circuitry-related PK. ${ }^{20}$

\section{Propofol for ECMO and VAD}

Propofol 2\% for ECMO and VAD may be able to overcome the disadvantage of $1 \%$ propofol. More research will bring forth results. This highly lipophilic and protein-bound sedative-hypnotic agent is largely sequestered into the ECMO circuit. The drug-related toxicity and concerns for propofol infusion syndrome (PRIS) call for caution in the prolonged use of this drug during neonatal ECMO. Higher dose of propofol may be required over time for optimal sedation on ECMO. $^{21}$ ( - Table 4)

\section{Dexmedetomidine for ECMO and VAD}

Dexmedetomidine helps in weaning from ECMO. Once primed, ECMO circuit was dosed with $840 \mu \mathrm{g}$ of dexmedetomidine 
for a final concentration of $0.9 \mu \mathrm{g} / \mathrm{mL}$. It is good as a sedative analgesic for $6.1 \pm 4.8$ days, with a low dose infusion of another sedative. Clonidine use and prescription during neonatal and pediatric ECMO is supported by a recent population PK study, which suggested higher clonidine doses, based on the increase of $\mathrm{Vd}$ and $\mathrm{CI}$ in the specific setting of ECMO and renal replacement therapy. Limited in vitro data are available for dexmedetomidine, which is partially sequestered into the circuit: a LD may be required, although recommendations for its long-term use cannot be provided ( Table 4) (Fig. 11). ${ }^{22}$

\section{Summary of drug physicochemical properties, ECMO-induced PK changes, and drug dosing- Flowchart 7}

\section{ECMO and VAD in ICU}

Both ECMO and VAD, needed in ICU, require sedation with intravenous agents. Morphine on ECMO remains the sedative analgesia of choice; dexmedetomidine is useful in weaning from ECMO by decreasing dosage of other drugs. Awake ECMO is becoming more practical today, as it brings in early ambulation and recovery. ${ }^{26}$

\section{Awake ECMO is the New Norm in 2021, with Help of Short-Acting TIVA Drugs}

Success of an awake ECMO are not just dependent on the percutaneous cannulation strategy and ECMO configuration, but also on the use of appropriate sedation and analgesia in the ICU. Some unstable patients may require a ECMO to be inserted under GA in the operating room.

The sedation plan for awake ECMO, should be meticulous. The sedation plan for ECMO and VAD must include techniques and TIVA drugs to achieve conscious sedation and comfort to allow for physiotherapy and mobilization first twenty four hours on ECMO may be with the use of a muscle relaxant but once ECMO goals are met, the aim is a sedation free period with an analgesic in place like fentanyl on flow or use dexmedetomidine infusion (if the haemodynamics permit) to ease a patient into conscious sedation. Patients should be evaluated and oriented to time and place once awake. All interventions must be explained to the patient when with reduced sedation, the patient awakens.

Table 4: Pharmacokinetics and dosing of some important drugs used in TIVA.

\begin{tabular}{|c|c|c|c|c|c|}
\hline $\begin{array}{l}\text { Drug class } \\
\text { references }\end{array}$ & Medication & Logp/PB\% & $\begin{array}{l}\text { ECMO-related PK } \\
\text { changes }\end{array}$ & $\begin{array}{l}\text { Standard dosing } \\
\text { in critically ill } \\
\text { term } \\
\text { neonates }\end{array}$ & $\begin{array}{l}\text { Dosing } \\
\text { recommendations } \\
\text { for neonates on } \\
\text { ECMO }\end{array}$ \\
\hline $\begin{array}{l}\text { Opioid } \\
\text { analgesics }^{8}\end{array}$ & Morphine & $0.99 / 30-40$ & $\begin{array}{l}\text { - In vitro: } \\
\text { mild-to-moder- } \\
\text { ate drug loss in } \\
\text { - temporary } \\
\text { ECMO systems. } \\
\text { - Clinical PK } \\
\text { studies (older } \\
\text { circuits): no } \\
\text { changes }\end{array}$ & $\begin{array}{l}\text { - Loading dose } \\
100 \mathrm{Mcg} / \mathrm{Kg} \text {. } \\
\text { Maintenance } \\
\text { Dose } 10-40 \\
\mathrm{Mcg} / \mathrm{Kg} / \mathrm{H}\end{array}$ & $\begin{array}{l}\text { Analgesic of } \\
\text { choice during } \\
\text { ECMO at most } \\
\text { centers. } \\
\text { - Minimal dose } \\
\text { adjustment may } \\
\text { be required. }\end{array}$ \\
\hline Benzodiazepine $^{23}$ & Midazolam & $3.89 / 97$ & $\begin{array}{l}\text { - In vitro: moder- } \\
\text { ate sequestration } \\
\text { - Clinical PK: } \\
\text { Increased Vd }\end{array}$ & $\begin{array}{l}\text { - Loading dose } \\
\text { 50-150 Mcg/Kg } \\
\text { Maintenance } \\
\text { Dose } 10-60 \\
\text { Mcg/Kg/H }\end{array}$ & $\begin{array}{l}\text { - consider increas- } \\
\text { ing the loading } \\
\text { dose in the early } \\
\text { phase of ECMO. } \\
\text { - Beware of drug/ } \\
\text { metabolites } \\
\text { accumulation } \\
\text { over time. }\end{array}$ \\
\hline $\begin{array}{l}\text { A2-adrenergic } \\
\text { agonist }^{24}\end{array}$ & $\begin{array}{l}\text { Dexmedetomidine } \\
\text { and ECMO and VAD } \\
\text { PK }\end{array}$ & $3.39 / 94$ & $\begin{array}{l}\text { - In vitro: moder- } \\
\text { ate sequestration } \\
\text { - No clinical PK }\end{array}$ & $\begin{array}{l}\text { - Loading dose } 1 \\
\text { Mcg/Kg. } \\
\text { Maintenance } \\
\text { dose } 0.2-0.7 \\
\text { Mcg/Kg/H }\end{array}$ & $\begin{array}{l}\text { - Although sparse, } \\
\text { data suggest } \\
\text { the need for a } \\
\text { loading dose }\end{array}$ \\
\hline Glycopeptide ${ }^{25}$ & $\begin{array}{l}\text { Vancomycin and } \\
\text { ECMO absorption }\end{array}$ & $-1.4 / 50$ & $\begin{array}{l}\text { - In vitro: large } \\
\text { increase in } \\
\text { Vd, mini- } \\
\text { mal-to-mod- } \\
\text { erate loss } \\
\text { conflicting } \\
\text { clinical PK data } \\
\text { in contemporary } \\
\text { circuits, in terms } \\
\text { of impact on CI }\end{array}$ & $\begin{array}{l}\text { - Postnatal age }<7 \\
\text { days: } 10-15 \mathrm{Mg} / \\
\text { Kg every } 8 / 12 \mathrm{H} \\
\text { - } 7 \text { days: } 15 \mathrm{Mg} / \\
\text { Kg every } 6 / 8 \mathrm{H}\end{array}$ & $\begin{array}{l}\text { Dosing guide- } \\
\text { lines based on } \\
\text { age and renal } \\
\text { clearance. } \\
\text { - Suggested dose } \\
\text { in neonates: } \\
\text { - Therapeutic } \\
\text { drug monitoring } \\
\text { for dosing }\end{array}$ \\
\hline
\end{tabular}




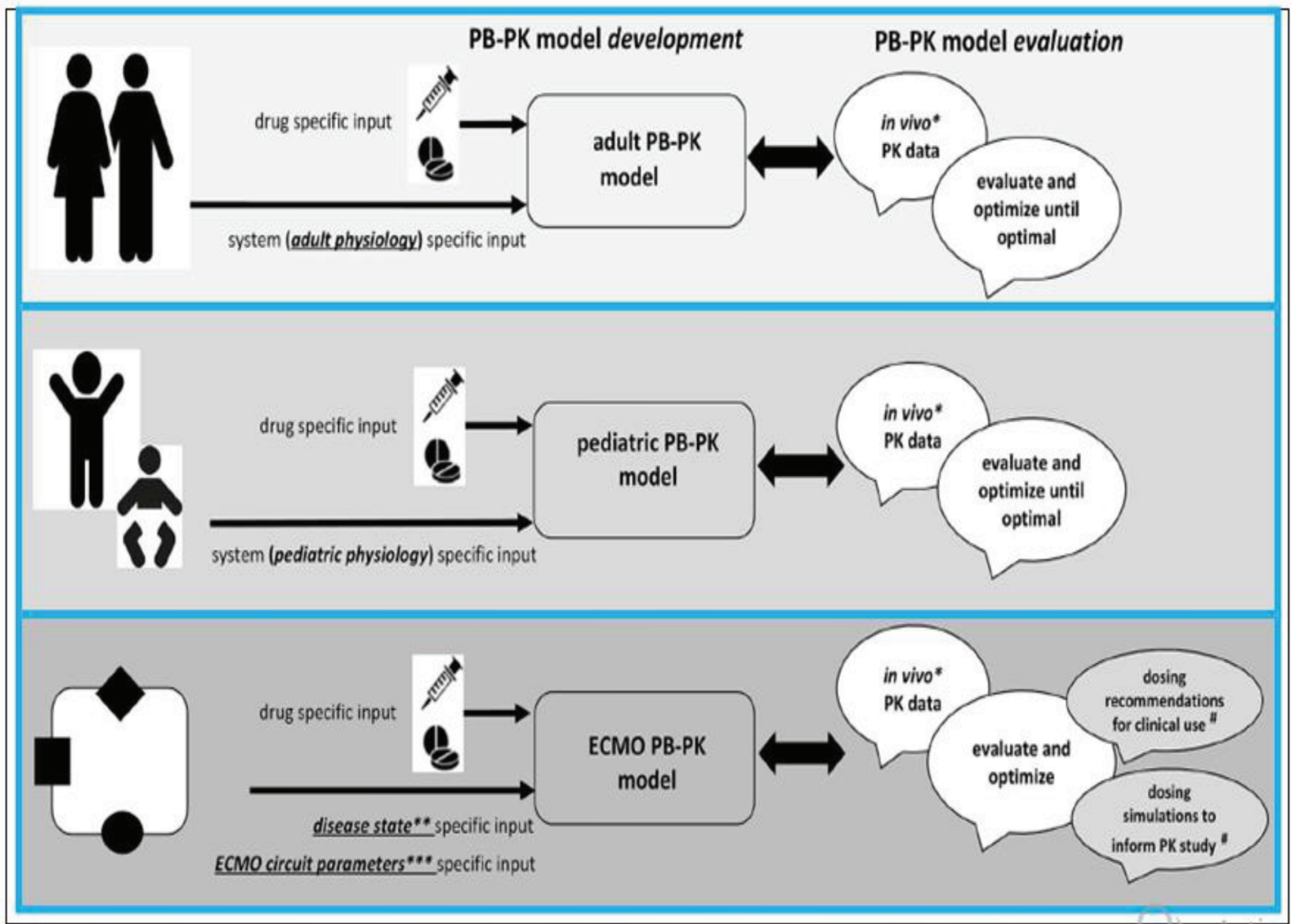

Fig. 9 Integrated approach for drug prediction through physiologically-based pharmacokinetic (PBPK) models during neonatal extracorporeal membrane oxygenation (ECMO).

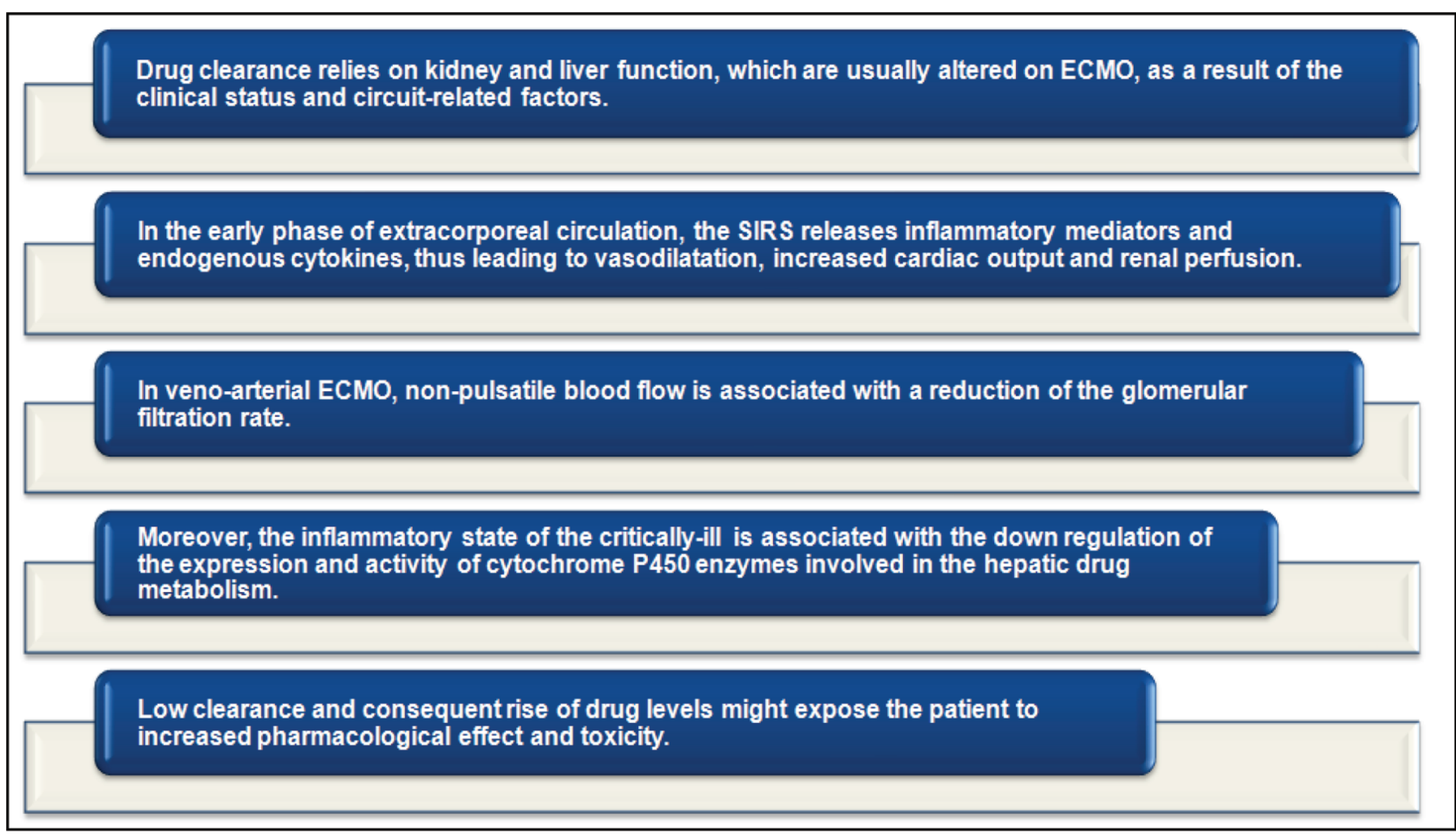

Fig. 10 ECMO-induced clearance variability ${ }^{17}$ 


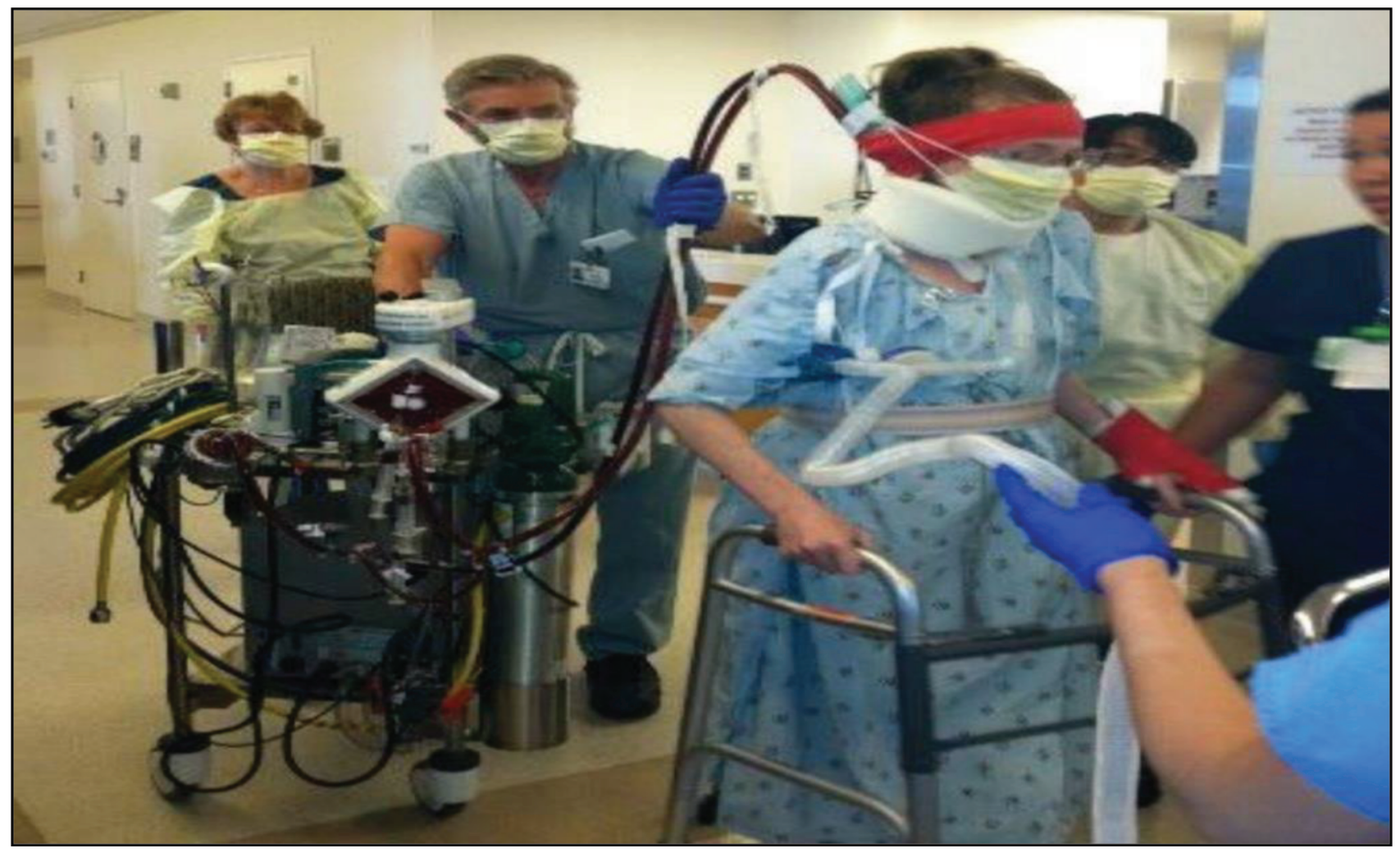

Fig. 11 A patient walking with extracorporeal membrane oxygenation (ECMO) machine in the ICU.

\section{Conclusion}

A "one-size-fits-all" approach to sed ation and analgesia management in patients on mechanical circulatory support (MCS) is problematic because of interpatient variability as well as subtle differences between devices. Rather, a team of dedicated and experienced providers must take multiple factors into consideration and adjust therapy accordingly. It is useful to have a standardized starting point for ECMO and VAD therapy, so that patients can be evaluated systematically and with a consistent approach, and early ambulation with TIVA should be practiced more as the use of ECMO and VAD increases in 2021.

\section{Conflict of Interest}

None declared.

\section{References}

1 Shekar K, Fraser JF, Smith MT, Roberts JA. Pharmacokinetic changes in patients receiving extracorporeal membrane oxygenation. J Crit Care 2012;27(6):741.e9-741.e18

2 Anesthetic Management of Patients on ECMO DOI: $10.5772 / 63309$

3 Tsai D, Lipman J, Roberts JA. Pharmacokinetic/pharmacodynamic considerations for the optimization of antimicrobial delivery in the critically ill. Curr Opin Crit Care 2015;21(5):412-420

4 Varghese JM, Roberts JA, Lipman J. Pharmacokinetics and pharmacodynamics in critically ill patients. Curr Opin Anaesthesiol 2010;23(4):472-478
5 Buck ML. Pharmacokinetic changes during extracorporeal membrane oxygenation: implications for drug therapy of neonates. Clin Pharmacokinet 2003;42(5):403-417

6 Mulla H, Lawson G, Firmin R, Upton DR. Drug disposition during extracorporeal membrane oxygenation (ECMO) Paediatr Perinat Drug Ther 2001;4(3):109-120

7 Shekar K, Roberts JA, Barnett AG, et al. Can physicochemical properties of antimicrobials be used to predict their pharmacokinetics during extracorporeal membrane oxygenation? Illustrative data from ovine models. Crit Care 2015;19(1):1-11

8 Wildschut ED, Ahsman MJ, Allegaert K, Mathot RA, Tibboel D. Determinants of drug absorption in different ECMO circuits. Intensive Care Med 2010;36(12):2109-2116

9 Shekar K, Roberts JA, Ghassabian S, et al. Sedation during extracorporeal membrane oxygenation-why more is less. Anaesth Intensive Care 2012;40(6):1067-1069

10 Buscher H, Vaidiyanathan S, Al-Soufi S, et al. Sedation practice in veno-venous extracorporeal membrane oxygenation: an international survey. ASAIO J 2013;59(6):636-641

11 Alcorn J, McNamara PJ. Pharmacokinetics in the newborn. Adv Drug Deliv Rev 2003;55(5):667-686

12 Shekar K, Roberts JA, Welch S, et al. ASAP ECMO: antibiotic, sedative and analgesic pharmacokinetics during extracorporeal membrane oxygenation: a multi-centre study to optimise drug therapy during ECMO. BMC Anesthesiol 2012;12:29

13 Shekar K, Roberts JA, Smith MT, Fung YL, Fraser JF. The ECMO PK Project: an incremental research approach to advance understanding of the pharmacokinetic alterations and improve patient outcomes during extracorporeal membrane oxygenation. BMC Anesthesiol 2013;13:7

14 Shekar K, Roberts JA, Mcdonald CI, et al. Protein-bound drugs are prone to sequestration in the extracorporeal membrane 
oxygenation circuit: results from an ex vivo study. Crit Care 2015;19:164

15 Poonam Malhotra Kapoor. Anticoagulation during ECMO: will the tight rope be tighter in 2018? Journal of Cardiac Critical Care TSS 2017;1(2):55-56

16 Sharma A, Sharan S, Kapoor PM, Chowdhury UK. COVID-19 ECMO Myths Busted. Journal of Cardiac Critical Care TSS. 2020;4(1):51-55

17 Mané C, Delmas C, Porterie J, et al. Influence of extracorporeal membrane oxygenation on the pharmacokinetics of ceftolozane/tazobactam: an ex vivo and in vivo study. J Transl Med 2020;18(1):213

18 Raffaeli G, Pokorna P, Allegaert K, et al. drug disposition and pharmacotherapy in neonatal ECMO: from fragmented data to integrated knowledge. Front Pediatr 2019;7:360

19 Verkerk BS, Dzierba AL, Muir J, et al. Opioid and benzodiazepine requirements in obese adult patients receiving extracorporeal membrane oxygenation. Ann Pharmacother 2020;54(2):144-150

20 Chanques G, Constantin JM, Devlin JW, et al. Analgesia and sedation in patients with ARDS. Intensive Care Med 2020; 46(12):2342-2356
21 Zimmerman KO, Dallefeld SH, Hornik CP, Watt KM. Sedative and analgesic pharmacokinetics during pediatric ECMO. J Pediatr Pharmacol Ther 2020;25(8):675-688

22 Bakdach D, Akkari A, Gazwi K, et al. Propofol safety in anticoagulated and nonanticoagulated patients during extracorporeal membrane oxygenation. ASAIO J 2020;(e-pub ahead of print). doi: 10.1097/MAT.0000000000001207

23 Raffaeli G, Allegaert K, Koch B, et al. In vitro adsorption of analgosedative drugs in new extracorporeal membrane oxygenation circuits. Pediatr Crit Care Med 2018;19(5):e251-e258, 10

24 Nasr VG, Meserve J, Pereira LM, et al. Sedative and analgesic drug sequestration after a single bolus injection in an ex vivo extracorporeal membrane oxygenation infant circuit. ASAIO J 2019;65(2):187-191

25 Moffett BS, Morris J, Galati M, Munoz F, Arikan AA. Population pharmacokinetics of vancomycin in pediatric extracorporeal membrane oxygenation. Pediatr Crit Care Med 2018;19(10):973-980

26 Lim JH, Kwak JG, Min J, et al. Experience with temporary centrifugal pump bi-ventricular assist device for pediatric acute heart failure: comparison with ECMO. Pediatr Cardiol 2020;41(8):1559-1568 